The Egyptian Journal of Hospital Medicine (January 2019) Vol. 74 (4), Page 949-956

\title{
The Role of Nuclear Factor Kappa B Rs28362491 Single Nucleotide Gene Polymorphism in Recurrent Embryo Implantation Failure
}

\author{
Khalid Tahseen Ahmed Gabr'1, Abd EL-Mohsen Mousa Shaheen', Ashraf Taha Abd-Elmouttaleb ${ }^{2}$ and Adel \\ Elsayed Ibrahim ${ }^{2}$ \\ ${ }^{1}$ Department of Medical Biochemistry, ${ }^{2}$ Assisted Reproductive Unit, International Islamic Center for Population \\ Studies and Research, Faculty of Medicine, Al-Azhar University \\ Corresponding author: Khalid Tahseen Ahmed Gabr; Phone: 01128518984; Email: dr_kh_g20252000@yahoo.com
}

\begin{abstract}
:
Background: Embryo implantation is a very intricate process, which is controlled by a number of complex molecules like hormones, cytokines, growth factors and their cross talk at feto-maternal interface. The transcription factor nuclear factor kappa B (NF- $\mathrm{BB})$ induces the expression of various pro-inflammatory genes, including those encoding cytokines and chemokines, and also participates in inflammasome regulation. Aim of the present study: was to investigate the possible associations between NF- $\mathrm{KB}$ rs28362491 single nucleotide gene polymorphism and susceptibility to repeated implantation failure (RIF). Subjects and Methods: This study was conducted on 120 subjects subdivided into 2 groups: 60 women with successful implantation as a control group (Group I), and 60 women diagnosed with RIF (Group II). They were subjected to full history taking, clinical examination and investigated for molecular testing of the NF- $\mathrm{kB}-94$ ins/del ATTG (rs28362491) polymorphism by lymphocyte separation and extraction of DNA for polymerase chain reaction (PCR) together with determination of serum concentration of day 3 follicle stimulating hormone (FSH), luteinizing hormone (LH), estradiol II (E2), prolactin and thyroid stimulating hormone (TSH) concentrations by an automated quantitative enzyme-linked fluorescent immunoassay (ELFA). Results: A significant difference in the genotype distribution of the NF- $\kappa \mathrm{B}$ rs 28362491 between those with RIF and controls. Specifically, subjects with RIF had a significantly higher frequency of the NF$\kappa \mathrm{B}$ rs28362491 del allele than that of controls. Conclusion: This study showed a significant association between rs28362491 in the promoter region of the NF- $\mathrm{BB}$ gene and RIF. NF- $\kappa \mathrm{B}$ appears to be a triggering factor of orchestrated gene regulation during embryo implantation.

Key words: Recurrent embryo Implantation Failure; Nuclear Factor Kappa B; single nucleotide gene polymorphism.
\end{abstract}

\section{INTRODUCTION}

Repeated implantation failure (RIF) is defined as three or more failed assisted reproductive technique (ART) attempts or pregnancy failure after 10 or more embryo transfers in multiple transports. It is often attributed to uterine failure to gain receptivity. For successful implantation a coordinated interaction between the receptive endometrium and developing blastocyst is required, this coordination is mediated by hormones, adhesive molecules, cytokines and growth factors at the feto-maternal interface. Cytokines such as leukemia inhibitory factor (LIF), interleukin 6 (IL6), interleukin 11 (IL-11) and transforming growth factor $\beta$ (TGF- $\beta$ ) have been determined as key cytokines for embryo implantation ${ }^{[1]}$.

Embryo implantation is associated with an effective inflammatory response from $\mathrm{T}$ helper type 1 (Th1) while $\mathrm{T}$ helper type 2 (Th2)-humoral inflammation is required to maintain pregnancy.
However, the results suggest that Th1 inflammatory response is also necessary to acquire uterine receptivity ${ }^{[2]}$. Human embryo implantation may occur only during a regulated "implantation window" on days 6-10 post ovulation and surrounded by refractory endometrial status ${ }^{[3]}$.

In 1986, David Biltmore and Coworkers identified the nuclear factor kappa $\mathrm{B}(\mathrm{NF}-\kappa \mathrm{B})$ as a factor in the nucleus of $\mathrm{B}$ cells that binds to the enhancer of the kappa light chain of immunoglobulin. It has been shown to be present in the cytoplasm of every cell in its inactive state and is conserved in all animals from Drosophila to man. It translocate to the nucleus only when it is activated, regulating the expression of more than 300 immune, growth and inflammatory genes ${ }^{[4]}$.

$\mathrm{NF}-\kappa \mathrm{B}$ is a major regulator for transcription of genes responsible for immune responses, apoptosis, 
The Role of Nuclear Factor Kappa B Rs28362491 Single Nucleotide Gene Polymorphism...

and control of cell growth. In previous studies, evidence suggests that NF- $\kappa \mathrm{B}$ plays a pivotal role in the development of RIF ${ }^{[5,6]}$. It is also believed to play important roles in opening the window of implantation and the first stage of embryo implantation ${ }^{[7]}$. NF- $\kappa B$ regulates pro-inflammatory genes and can be involved in inflammation associated with implantation ${ }^{[8]}$. All these processes are characterized by a specific immune response at the maternal-fetal interface that permits the invasion of trophoblast and angiogenesis; it protects the maternal tissue from over-invasion of the trophoblast in early pregnancy ${ }^{[9]}$.

The aim of the present study was to investigate the possible associations between NF- $\kappa \mathrm{B}$ rs28362491 single nucleotide gene polymorphism and susceptibility to repeated implantation failure (RIF).

\section{SUBJECTS AND METHODS}

This study included a total of $\mathbf{1 2 0}$ women under the age of forty who were subjected to embryo implantation. They were selected from Assisted Reproductive Unit, International Islamic Center for Population Studies and Research, Al-Azhar University, Cairo. Approval of the ethical committee and a written informed consent from all the subjects were obtained. This study was conducted between (January 2017, and June 2018).

Subjects were categorized into 2 groups. Group I: 60 women with successful implantation with transfers of $\geq 1$ high-quality (grades I and II) fresh or frozen-thawed embryos used as a control group.Their age ranges from (24 - 37) with a mean value of $(31.68 \pm 4.46)$, and their Body Mass Index (BMI) ranges from (23.59 - 32.53) with a mean value of $(27.43 \pm 1.98)$. Group II: 60 women diagnosed with repeated implantation failure and had $\geq 3$ failed embryo transfers (ET) with transfers of $\geq 1$ highquality (grades I and II) fresh or frozen-thawed embryos were included in this study. These women had a normal endometrial thickening $(7-12 \mathrm{~mm})$ on the day of oocyte retrieval with no detection of endometrial pathology diagnosed by TVS (Transvaginal sonography) and reported in patient's file in the assisted reproductive unit. Their age ranges from (26 - 39) with a mean value of $(32.22 \pm 3.77)$, also their body mass index (BMI) ranges from (23.53 $32.11)$ with a mean value of $(26.97 \pm 2.07)$.

Exclusion criteria: Women over the age of forty or had less than 3 failed embryo transfers (ET)

Laboratory assessments of the measured parameters in the different submitted groups are presented in the or with haematological, immunological, hormonal disorders or uterine abnormalities (acquired or congenital) were excluded.

All women answered a questionnaire, which contains details of age, medical history, previous trials for embryo transfers and successful implantation. These data was recorded in a structured protocol format.

Specimen collection: $10 \mathrm{ml}$ of venous blood were withdrawn and divided into two $5 \mathrm{ml}$ tubes; EDTA containing tube for molecular testing of the NF-кB $\quad-94$ ins/del ATTG (rs28362491) polymorphism and plain tube for separation of serum that used to estimate the concentrations of day 3 follicle stimulating hormone (FSH), luteinizing hormone (LH), estradiol II (E2), prolactin and thyroid stimulating hormone (TSH).

Molecular testing of the NF-кB [-94 ins/del ATTG rs28362491] polymorphism was done by lymphocyte separation according to Böyum, A method ${ }^{[10]}$ followed by extraction of DNA for polymerase chain reaction-restriction fragment length polymorphism (PCR-RFLP) method according to the protocol of Tuncay et al. ${ }^{[11]}$.

For Hormonal Assay, determination of day 3 follicle stimulating hormone (FSH), luteinizing hormone (LH), estradiol II (E2), prolactin and thyroid stimulating hormone (TSH) was done as a routine investigation in the lab of the Assisted Reproductive Unit of the International Islamic Centre for Population Studies and Research Al-Azhar University, Cairo, Egypt. The assay was done by an automated quantitative enzyme-linked fluorescent assay (ELFA) ${ }^{[12]}$ by vidas, biomerieux, France.

\section{STATISTICAL ANALYSIS}

In addition to the descriptive data, statistical analysis was done using IBM Statistical Package for the Social Sciences (SPSS) STATISTC VERSION 20 PROGRAM. Data were expressed as Range, Mean \pm Standard deviation (SD) and analyzed using the Chisquare $\left(\mathrm{x}^{2}\right)$ test and the Student's test to assess the significance of difference between different parameters. $\mathrm{P}<0.05$ was accepted as significant. Correlation coefficient (r) of two variables was also done by using Pearson correlation coefficient (r) with $\mathrm{P}$ value calculation.

\section{RESULTS}


following tables and figures:

- As regard Age (year) and body mass index (BMI) levels; there was statistically no significant difference among patients with RIF [group II] and controls with successful implantation [group I] [figure 1].

Levels

Age (years) and Body Mass Index (BMI) levels.

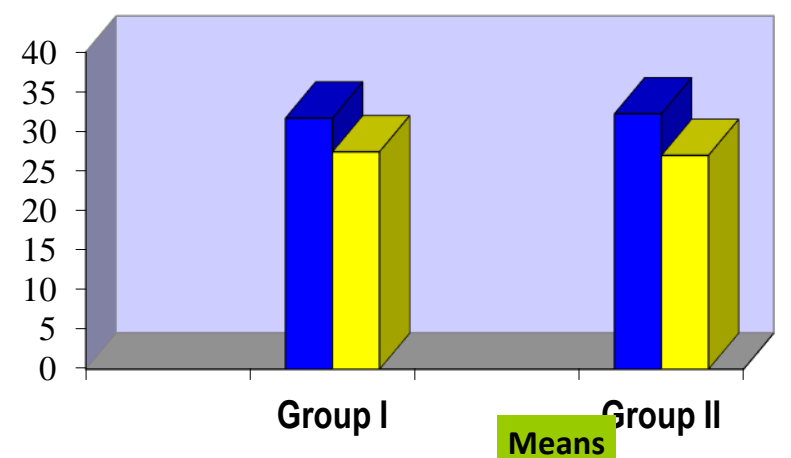

Figure [1]: Comparison between studied groups as regard Age (year) and body mass index (BMI) levels.

- As regard genotypic and allelic frequencies of NF- $\mathrm{BB}$ (rs28362491) polymorphisms; there was a statistically significant difference between patients with RIF [group II] and controls with successful implantation [group I]). Particularly, the frequency of the del/del genotype was significantly higher in RIF patients $(63.3 \%)$ than that in controls (3.3\%) with P value $<0.00001$ [table 1]. Specifically, compared with controls, the RIF patients carried a higher frequency of the rs 28362491 del allele $(78.3 \%)$ with $\mathrm{P}$ value $<0.00001$ [table 2].

TABLE [1] shows the genotypic frequencies of NF- $\mathrm{kB}$ (rs28362491) polymorphisms in controls and patients with RIF

\begin{tabular}{|l|c|c|c|c|c|}
\hline & \multicolumn{3}{|c|}{ Genotype [N (\%)] } & \multirow{2}{*}{$\begin{array}{c}\text { Chi square } \\
(\mathbf{x} 2) \text { test }\end{array}$} & $\begin{array}{c}\text { P } \\
\text { value }\end{array}$ \\
\cline { 2 - 4 } & ins/ins & ins/del & del/del & & \\
Group I (No=60) & $48(80 \%)$ & $10(16.7 \%)$ & $2(3.3 \%)$ & & \\
\cline { 1 - 4 } Group II (No=60) & $4(6.7 \%)$ & $18(30 \%)$ & $38(63.3 \%)$ & 71.92 & $<0.00001$ \\
\hline
\end{tabular}

*Calculation was done by using $\underline{\text { Chi square }(x 2) \text { test. }} \quad * \mathbf{P}$ value is significant $<0.05$.

TABLE [2] shows the allelic frequencies of NF-kB (rs28362491) polymorphisms in controls and patients with RIF

\begin{tabular}{|l|c|c|c|c|}
\hline & \multicolumn{2}{|c|}{ Allele [N(\%)] } & \multirow{2}{*}{$\begin{array}{c}\text { Chi square } \\
\text { (x2) test }\end{array}$} & $\begin{array}{c}\text { P } \\
\text { value }\end{array}$ \\
\cline { 2 - 3 } & Insertion & deletion & & \\
\hline Group I (No=60) & $106(88.3 \%)$ & $14(11.7 \%)$ & & \\
\hline Group II (No=60) & $26(21.7 \%)$ & $94(78.3 \%)$ & 107.74 & $<0.00001$ \\
\hline
\end{tabular}

*Calculation was done by using $\underline{\text { Chi square }(x 2) \text { test. }} \quad * \mathbf{P}$ value is significant $<0.05$.

- The exposure to rs28362491 [del] of the NF- $\mathrm{KB}$ is associated with a higher frequency of RIF in IVF Assisted patients (odds ratio $=30.29,95 \%$ C.I. $=14.82-61.89$ ) [table 3].

TABLE [3] shows the odds ratio calculation

\begin{tabular}{|l|c|c|c|}
\hline \multirow{2}{*}{ Odds ratio } & \multicolumn{2}{|c|}{ 95\% Confidence Intervals } \\
\cline { 3 - 4 } & 30.29 & Upper limit & Lowe limit \\
\hline observation & Ong & 61.89 & 14.82 \\
\hline
\end{tabular}

*Calculation was done by using odds ratio calculator.

- As regard serum concentration of day $3 \mathrm{FSH}[6.89 \pm 1.72,6.75 \pm 1.77], \mathrm{LH}[8.51 \pm 1.88,8.37 \pm 2.42]$, estradiol II (E2) $[82.02 \pm 28.17,85.93 \pm 27.12]$, prolactin $[15.15 \pm 6.44,13.78 \pm 4.76]$ and TSH $[2.29 \pm 1.05,2.59 \pm$ 
The Role of Nuclear Factor Kappa B Rs28362491 Single Nucleotide Gene Polymorphism...

1.19] for both patients and controls respectively they were within the normal levels of reference values [table $4]$.

TABLE [4] shows the distribution of serum concentrations of day 3 FSH, LH, estradiol II (E2), Prolactin and TSH among the studied groups

\begin{tabular}{|c|c|c|c|c|c|}
\hline & \multicolumn{5}{|c|}{ Mean \pm Standard Deviation (SD) for Hormonal Assay } \\
\hline Hormones & $\begin{array}{c}\begin{array}{c}\text { FSH } \\
(\mathrm{mIU} / \mathrm{ml})\end{array} \\
\end{array}$ & $\begin{array}{c}\text { LH } \\
(\mathrm{mIU} / \mathrm{ml}) \\
\end{array}$ & $\begin{array}{c}\text { Estradiol II (E2) } \\
(\mathrm{Pg} / \mathrm{ml})\end{array}$ & $\begin{array}{l}\text { Prolactin } \\
(\mathrm{mIU} / \mathrm{ml})\end{array}$ & $\begin{array}{c}\text { TSH } \\
\text { (IU/ml) } \\
\end{array}$ \\
\hline Group I (No=60) & $6.75 \pm 1.77$ & $8.37 \pm 2.42$ & $85.93 \pm 7.12$ & $13.78 \pm 2.76$ & $2.59 \pm 0.19$ \\
\hline Group II (No=60) & $6.89 \pm 1.72$ & $8.51 \pm 1.88$ & $82.02 \pm 8.17$ & $15.15 \pm 3.44$ & $2.29 \pm 0.05$ \\
\hline
\end{tabular}

* Mean and Standard Deviation were calculated by using $\underline{\text { Student's } \boldsymbol{t} \text { Test. }}$.

\section{DISCUSSION}

This study addresses the major rate-limiting step for successful treatment of infertility by assisted reproductive technology (ART). Moreover, at present in many couples the cause of their infertility is not identified.

Successful embryo implantation is a process that requires both a synchronous development and interaction between hatched blastocyst and endometrium. Repeated implantation failure (RIF) indicates failure to achieve a clinical pregnancy after at least four good quality embryos were transferred from at least three fresh or frozen cycles in a woman under the age of 40 years ${ }^{[13]}$. Until now, most attempts to improve IVF implantation rate have focused on embryonic factors. By contrast, few interventions have been proposed to improve endometrial receptivity, although there is evidence that up to two thirds of implantation failure cases could be secondary due to inadequate receptivity ${ }^{[14]}$.

Nuclear factor kappa B [NF- $\mathrm{B}$ ] proteins are a family of structurally related eukaryotic transcription factors that are persistently active in the pathogenesis of numerous malignancies ${ }^{[15]}$ in addition to RIF ${ }^{[5,6]}$. NF- $\kappa \mathrm{B}$ is a transcription factor involved in the regulation of genes related to inflammation and immune response. It is also believed to play important roles in opening the window of implantation and the first stage of implantation ${ }^{[16]}$.

Genetic variation contributes to different disease susceptibility. The functional significance of rs28362491 [-94 ins/del ATTG], has been well elucidated. The NF-кB [-94 ins/del] ATTG promoter polymorphism is an insertion/deletion of four bases in the promoter region of the NF- $\kappa B$ gene that encodes for the p50 subunit and the variant allele containing this deletion produces lower transcript levels of the p50 subunit ${ }^{[17]}$. The NF-kB1 rs28362491 promoter polymorphism is the only known functional polymorphism in the NF-KB family ${ }^{[18,19]}$.

The present study hypothesized that the NF$\kappa \mathrm{B}$ is one of the most important mediators of inflammatory cytokines expressed in the endometrium. Both the production and release of these cytokines change in women with failed implantation and according to the fact that Implantation is an inflammatory process that is characterized by secretion of growth factors and cytokines including $\mathrm{TNF} \alpha$, cyclooxygenase derived prostaglandins and NF- $\kappa \mathrm{B}$ from the fetomaternal surface; aberrant secretion of these inflammatory molecules might be responsible for the failed expression of the endometrial receptivity genes.

The current study investigated NF- $\mathrm{kB}-94$ ins/del ATTG promoter polymorphisms to seek further insight into the relationship between recurrent implantation failure after IVF-embryo transfer and this polymorphism.

The present Study showed that there were statistically significant differences in the genotype and allele frequency distributions of rs28362491 between the RIF patients [Group II] and controls [Group I]. Particularly, the frequency of the del/del genotype was significantly higher in RIF patients than that in controls [P value $=<0.00001]$. Specifically, compared with controls, the RIF patients carried a higher frequency of the rs28362491 [del] allele [P value $=<0.00001]$. The current study also showed that exposure to rs 28362491 [del] of the NF- $\kappa B$ is associated with a higher frequency of RIF in IVF assisted patients (odds ratio $=30.29,95 \%$ C.I. $=14.82-61.89$ ). For exclusion of hormonal imbalance as a cause of 
RIF; both patients and controls of the present study were selected to have day $3 \mathrm{FSH}$, LH, estradiol II (E2), prolactin and TSH within the normal levels of reference values.

The results of this study add to the increasing accumulation of data supporting the concept that genetic risk factors other than chromosomal abnormalities contribute to the unexplained causes of implantation failure. However, it is not likely that a single gene mutation would be the only cause of implantation failure. Evolutionary pressures would be expected to eliminate the mutated gene over time. It seems more likely that a combination of mutations rather than a single mutation contributes to the risk of recurrent implantation failure. The current challenge is to identify the combination of markers that are clinically useful in identifying and explaining the risk for recurrent implantation failure.

The present study is one of the first few studies to identify a significant association between rs28362491 in the promoter region of the NF- $\kappa \mathrm{B}$ gene and RIF. The same results were concluded by Luo et al. ${ }^{[20]}$ who stated that in a large and homogeneous population; NF- $\mathrm{BB}$ [rs28362491] gene polymorphisms were associated with RIF. They found a significant difference in the genotype distribution of rs28362491 between those with RIF and controls. Specifically, subjects with RIF had a significantly higher frequency of the rs 28362491 [del] allele than that of controls.

The current study was in agreement with Sakowicz, [21] who stated that there is a considerable body of experimental evidence suggests a strong association between NF- $\mathrm{KB}$ and the development of pregnancy. NF- $\kappa \mathrm{B}$ is perceived as an important regulator of implantation. An incorrect level of NF- $\kappa \mathrm{B}$ for the appropriate stage of pregnancy may predispose women to obstetric complications. Also knowledge about the management of NF- $\mathrm{KB}$ level in physiological and pathological pregnancy could provide the basis for the development of new strategies of treatment. Concordantly; Cakmak et al. ${ }^{[5]}$ supported the current study by it is conclusion that NF-kappa B may take a role in enhanced endometrial cell survival, altered immune response, and differential cytokine and chemokine expression especially for recurrent reproductive failure and implantationrelated infertility. Also, in line with current study was the conclusion of Dharmaraj et al. ${ }^{[6]}$ who stated that pro-inflammatory cytokines, including $\mathrm{TNF} \alpha$ and interferon $\gamma[\mathrm{IFN} \gamma]$ are highly expressed in uterine tissues via their downstream transcription factors, nuclear factor $[\mathrm{NF}-\kappa \mathrm{B}]$ and signal transducers and activators of transcription. They also concluded that the interplay among cytokine-activated transcription factors may have important consequences in both normal and pathological contexts, e.g. implantation failure and recurrent miscarriages. The current study is also supported by King et $\boldsymbol{a l} .{ }^{[8]}$ study that provides evidence supporting a role for NF- $\kappa \mathrm{B}$ pathway in the inflammatory events associated with menstruation and in the regulation of mediators crucial to successful implantation.

Concordantly, larid et al. ${ }^{[22]}$ supported the current study by it is conclusion that the expression of rel-A (avian reticulo-endotheliosis viral oncogene) in human endometrium for the first time and suggested that epithelial cell expression of rel$A$ is cyclical and maximal at time of implantation. Also the inhibition of IL-1 and TNF $\alpha$ stimulated IL-6 and LIF production by the NF- $\kappa \mathrm{B}$ inhibitors SN50 (a peptide, which binds to activated $N F-\kappa B$ and prevents its translocation to the nucleus) and MG132 (inhibits enzymatic activity of the proteasome, thus preventing IkB breakdown) suggests that NF- $\kappa \mathrm{B}$ components play an active role in the signaling pathways between the receptors for IL-1 and TNF $\alpha$ and the production of IL-6 and LIF in this tissue. Also, in line with current study was the conclusion of Kwak-Kim et al. ${ }^{[23]}$ who stated that the endometrium has a spectrum of cells which influence implantation and early trophoblast invasion. Later in the pregnancy, uterine natural killer ( $\mathrm{uNK}$ ) and peripheral natural killer (pNK) cells play a major role in pregnancy outcome as they influence or directly secrete cytokines which influence trophoblast invasion and aid in placental growth. Unbalance between Th1 and Th2 immunity, and Th17 and regulatory T-cell immunity may explain underlying immunepathology of reproductive failures such as recurrent pregnancy losses [RPL] or multiple implantation failures [MIF].

In contrast to the current study Ersahin et al. ${ }^{\text {[24] }}$ provided an evidence for abnormally increased endometrial NF- $\kappa \mathrm{B}$ expression in RIF participants and concluded that the disturbance of physiological expression pattern of NF- $\mathrm{KB}$ in the endometrium might contribute for the failed implantation observed in RIF women.

The present study was also supported by

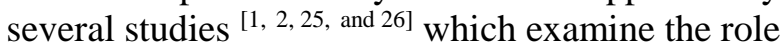
of soluble mediators whose transcription controlled by NF- $\kappa \mathrm{B}$. 
One of these studies stated that the Leukemia inhibitory factor (LIF) may be a predictor for unreceptive endometrium in cases of unexplained infertility [3]. Another research stated that the expression of LIF was moderate in the proliferative phase and higher in the secretory phase of fertile women. However, lower expression of LIF was found in unexplained infertile women with multiple implantation failure compared to fertile ones. Data suggested that the initial lower expression of LIF in proliferative phase may be one of the causes for multiple failure of implantation. Maternal LIF is essential for implantation; it affects trophoblast growth and development and has been described as a marker of the embryo implantation process ${ }^{[27]}$.

In contradiction to the above studies, It has been shown in another investigation that there is an association between day 11 IFN- $\gamma$ concentration and poor outcome of ART trial ${ }^{[28]}$, while another study did not support this finding ${ }^{[29]}$.

The current study also suggested that the implantation failure can be attributed to the impact of NF- $\mathrm{KB}$ on progesterone receptor that may impair endometrial receptivity of RIF women. Dharmaraj et al. ${ }^{[6]}$ supported this assumption and noted the positive relation between progesterone receptor and NF- $\mathrm{KB}$ expression supporting the critical role of this transcription factor for achieving blastocyst implantation. Moreover, Yang \& Wang ${ }^{[30]}$ reported that NF- $\kappa$ B action in living tissue is realized by microRNAs. Therefore, the impact of $\mathrm{NF}-\kappa \mathrm{B}$ on progesterone receptor might be mediated by microRNAs. Conversely, the existence of reciprocal antagonism between progesterone receptor and NF- $\mathrm{KB}$ p65 expression was demonstrated ${ }^{[31]}$.

In conclusion the current study showed a significant association between rs28362491 in the promoter region of the NF- $\mathrm{NB}$ gene and RIF. It demonstrates that the NF- $\kappa \mathrm{B}$ pathway may be responsible for the regulation of DNA transcriptions, immune responses, and activation of relevant genes related to the process of embryo implantation. Among these genes, those for cytokines, growth factors, and metalloproteinases, whose transcription may be activated or suppressed by NF- $\kappa \mathrm{B}$ during the early phase of pregnancy and around the implantation period. Also it demonstrates that pathological endometrial inflammation could be detrimental on progesterone effect on endometrium. Collectively, NF- $\mathrm{BB}$ appears to be a triggering factor of orchestrated gene regulation during implantation. Also, by leading progesterone resistance, disturbed NF- $\mathrm{kB}$ expression may impair endometrial receptivity of RIF women. However, the detailed functions of $\mathrm{NF}-\kappa \mathrm{B}$ during implantation need to be further elucidated.

Further investigation should be mandatory to elucidate the inducer of NF- $\mathrm{KB}$ activation, as well as the target of the activated NF- $\kappa \mathrm{B}$. Knowledge about the management of NF- $\kappa B$ level in physiological and pathological pregnancy could provide the basis for the development of new strategies of treatment. The design of targeted therapy directly against NF- $\mathrm{KB}$ seems promising and could be more effective than the current methods of medication.

\section{REFERENCES}

1- Rajaei S, Zamani A, Jeddi-Tehrani M et al. (2011): Cytokine profile in the endometrium of normal fertile and women with repeated implantation failure. Iranian Journal of Immunology, 8(4): 201-208.

2- Granot I, Gnainsky Y, Dekel N (2012): Endometrial inflammation and effect on implantation improvement and pregnancy outcome. Reproduction, 144(6): 661-668.

3- El-Zenneni H, Moustafa R, Eldeen $\mathrm{M}$ et al. (2017): Assessment of Sub-Endometrial Blood Flow and Endometrial Leukemia Inhibitory Factor as a Marker for Endometrial Receptivity in Women with Unexplained Infertility. Egyptian Journal of Hospital Medicine, 69:5.

4- Sen R \& Baltimore D (1986): Multiple nuclear factors interact with the immunoglobulin enhancer sequences. Cell, 46(5): 705-716.

5- Cakmak H, Guzeloglu-Kayisli O, Kayisli U et al. (2009): Immune-endocrine interactions in endometriosis. Front Biosci , 1(2): 429-443.

6- Dharmaraj N, Wang P, Carson D (2010): Cytokine and progesterone receptor interplay in the regulation of MUC1 gene expression. Molecular endocrinology, 24(12): 2253-2266.

7- Lindström T \& Bennett P (2005): The role of nuclear factor kappa B in human labour. Reproduction, 130(5): 569-581.

8- King A, Critchley H, Kelly R (2001): The NF$\kappa \mathrm{B}$ pathway in human endometrium and first trimester decidua. Molecular human reproduction, 7(2): 175-183.

9- Morelli S, Mandal M, Goldsmith, L et al. (2015): The maternal immune system during pregnancy and its influence on fetal 
development. Research and Reports in Biology, 6: 171-189.

10- Böyum A (1968): Isolation of mononuclear cells and granulocytes from human blood. Isolation of monuclear cells by one centrifugation, and of granulocytes by combining centrifugation and sedimentation at 1 g. Scandinavian journal of clinical and laboratory investigation. Supplementum, 97: 77-89.

11- Tuncay S, Okyay P, Bardakci F (2010): Identification of NF- $\mathrm{BB} 1$ and NF- $\mathrm{KBI} A$ polymorphisms using PCR-RFLP assay in a Turkish population. Biochemical genetics, 48(1-2): 104-112.

12- Anckaert E, Mees M, Schiettecatte J et al. (2002): Clinical validation of a fully automated $17 \beta$-estradiol and progesterone assay (VIDAS®) for use in monitoring assisted reproduction treatment. Clinical chemistry and laboratory medicine, 40(8): 824-831.

13- Coughlan $C$, Ledger $W$, Wang $Q$ et al. (2014): Recurrent implantation failure: definition and management. Reproductive biomedicine online, 28(1): 14-38.

14- $\quad$ Franasiak J , Scott R (2018): Embryo and Endometrial Synchrony in Implantation Failure. In Recurrent Implantation Failure 21-. Springer, Cham.

15- Hua T, Qinsheng W, Xuxia W et al. (2014): Nuclear Factor-kappa B1 is Associated with Gastric Cancer in a Chinese Population. Medicine, 93(28): e279.

16- Lindström $T$, Bennett $P$ (2005): The role of nuclear factor kappa B in human labour. Reproduction, 130(5): 569-581.

17- Van der Heiden K, Cuhlmann S, Luong L et al. (2010): Role of nuclear factor $\kappa \mathrm{B}$ in cardiovascular health and disease. Clinical Science, 118(10): 593-605.

18- Vogel U, Jensen M, Due K et al. (2011): The NF-KB ATTG ins/del polymorphism and risk of coronary heart disease in three independent populations. Atherosclerosis, 219(1): 200-204.

19- Choi Y, Choi Y. S, Kim Y et al. (2017): A multifunctional alanine-rich antiinflammatory peptide BCP61 showed potent inhibitory effects by inhibiting both NF- $\mathrm{KB}$ and MAPK expression. Inflammation, 40(2): 688696.

20- Luo L, Li D, Li $\mathrm{X}$ et al. (2016): Polymorphisms in the nuclear factor kappa B gene association with recurrent embryo implantation failure. Genet Mol Res., 15(2): gmr7759.

21- $\quad$ Sakowicz A (2018): The role of $\mathrm{NFKB}_{\mathrm{K}}$ in the three stages of pregnancy: implantation, maintenance and labour; a review article. An International Journal of Obstetrics \& Gynaecology, 125(11):1379-1387.

22- Laird S, Tuckerman E, Cork B et al. (2000): Expression of nuclear factor $\kappa \mathrm{B}$ in human endometrium; role in the control of interleukin 6 and leukaemia inhibitory factor production. Molecular human reproduction, 6(1): 34-40.

23- Kwak-Kim J, Bao S, Lee S et al. (2014): Immunological modes of pregnancy loss: inflammation, immune effectors, and stress. American Journal of Reproductive Immunology, 72(2): 129-140.

24- $\quad$ Ersahin A, Acet M, Acet T et al. (2016): Disturbed endometrial NF- $\mathrm{BB}$ expression in women with recurrent implantation failure. Eur Rev Med Pharmacol Sci., 20(24): 5037-5040.

25- Boomsma C, Kavelaars A, Eijkemans M et al. (2009): Endometrial secretion analysis identifies a cytokine profile predictive of pregnancy in IVF. Human reproduction, 24(6):1427-1435.

26- Inagaki $\mathrm{N}$, Stern $\mathrm{C}$, McBain $\mathrm{J}$ et al. (2003): Analysis of intra-uterine cytokine concentration and matrix-metalloproteinase activity in women with recurrent failed embryo transfer. Human Reproduction, 18(3): 608-615.

27- Wu M, Yin Y, Zhao M et al. (2013): The low expression of leukemia inhibitory factor in endometrium: possible relevant to unexplained infertility with multiple implantation failures. Cytokine, 62(2):334-339.

28- $\quad$ Ng S, Gilman-Sachs A, Thaker $P$ et al. (2002): Expression of intracellular Th1 and $T h 2$ cytokines in women with recurrent spontaneous abortion, implantation failures after IVF/ET or normal pregnancy. American Journal of Reproductive Immunology, 48(2): 77-86.

29- Ginsburg E, Xiao L, Gargiulo A et al. (2005): T-helper 2 and 3 type immunity to trophoblast in successful in vitro fertilizationembryo transfer. Fertility and sterility, 83(6): 1659-1664.

30- $\quad$ Yang Y , Wang J (2016): The functional analysis of microRNAs involved in NF- $\kappa \mathrm{B}$ signaling. Eur Rev Med Pharmacol Sci, 20(9): 1764-1774. 
The Role of Nuclear Factor Kappa B Rs28362491 Single Nucleotide Gene Polymorphism...

31- Kalkhoven E, Wissink S, van der Saag P et al. (1996): Negative interaction between the RelA (p65) subunit of NF-B and the progesterone receptor. Journal of Biological Chemistry, 271(11): 6217-6224. 